Preliminary results on the cultural adaptation of assessment instruments for distress and psychological well-being on Romanian population of parents having children with disabilities

Carmen Costea-Bărluțiu, Andrea Hathazi, Cristina Bălaș-Baconschi 


\title{
Preliminary results on the cultural adaptation of assessment instruments for distress and psychological well-being on Romanian population of parents having children with disabilities
}

\author{
Carmen Costea-Bărluțiu ${ }^{a^{*}}$, Andrea Hathazi ${ }^{b}$, Cristina Bălaș-Baconschi ${ }^{c}$ \\ a,b,c Special Education Department, Babeş-Bolyai University, 7 Sindicatelor Street, 400029, Cluj-Napoca, Romania \\ *Corresponding author: carmen.costea@ubbcluj.ro
}

\section{Abstract}

\section{Keywords:}

parental distress, wellbeing, culturally adapted measures, disability
Parental involvement in the lengthy and complex process of rehabilitation of children with various disabilities is essential for the effectiveness of the interventions. Parental involvement was associated with the levels of parental distress and well-being and parents of children with disabilities often demonstrate a higher level of distress and lower level of wellbeing, compared to parents of typically developed children. Careful consideration of the parents' needs holds high relevance in the rehabilitation process and, subsequently, there is a need to assess both parental well-being and distress using reliable and culturally adapted measures. Our paper reviews the results of several studies concerning parental distress and well-being and presents the results that we obtained in the attempt to culturally adapt two measures of the constructs on Romanian population, so that professionals in the field of special education can have the opportunity to use these measures in their work with parents, in order to help them cope with their child's disability and motivate them to better participate in the rehabilitation process.
Zusammenfasung

\section{Schlüsselwörter:}

Elternleid,

Wohlbefinden, kulturell angepasste Instrumente, Behinderung
Die Elternbeteiligung am schwierigen und langen Erholungsprozess von behinderten Kindern ist entscheidend für die Wirksamkeit der Maßnahmen. Die Elternbeteiligung steht in enger Verbindung mit dem Belastungsniveau der Eltern sowie mit Behaglichkeit; die Eltern von behinderten Kindern weisen oftmals höheren Leidungsgrad und niedrigeren Behaglichkeitsniveau als Eltern von normal entwickelten Kindern auf. Ein sorgsamer Umgang mit den Bedürfnissen solcher Eltern ist entscheidend für die Erholung des Kindes; daher ist die Beurteilung des Wohlbefindens sowie des Leids der Eltern anhand von wirksamen und kulturell angepassten Instrumenten äußerst wichtig. Unsere wissenschaftliche Arbeit ist ein Überblick über die Ergebnisse des Anpassungsversuchs zweier Instrumente an die rumänische Bevölkerung, nämlich ein Leitfaden für die im Bereich der pädagogischen Psychologie tätigen Fachleute in der Zusammenarbeit mit Eltern, die im Umgang mit der Behinderung ihres Kindes sowie in der Beteiligung am Erholungsprozess eingewiesen werden.

\section{Introduction. The role of parental distress and} family well-being in the educational process of the child with disabilities

In the complex process of rehabilitation of children with disabilities, the family holds an essential role, therefore the complete involvement of the family needs to be taken into consideration by the special education teachers involved in the education of children with disabilities. The increased level of parental distress influences the parents' capacity to adapt to the needs of their children and to offer a proper care (Agazio \& Buckley, 2012), thus influencing the frequency of the behavioral problems of children with intellectual disability (Beck, Hastings, Daley, \& Stevenson, 2004).
Parental distress has also been related with the parental involvement in the education process of children, as well as with their academic performance. In the case of a group of children with ADHD, the higher level of parental distress was related with the increased use of strategies of child control, and the decreased level of parental distress was related with the supportive style of the parents regarding the child's education. In the first situation, the child with ADHD showed a more severe symptomatology and reduced academic success, while in the second situation, the child's ADHD symptoms were less severe, and the performance level was higher (Rogers, Wiener, Marton, \& Tannock, 2009).

In the family, the child's disability can be an important distress factor, influencing the adaptation to the challenges 
of daily life, the well-being of both the family as a system, and the individual members. The burden of several roles, the fears about the child's future, the multitude of difficult experiences that the family transitions across different life cycles can significantly influence family life, and their effect can be felt in the involvement of parents in their child's education and in the relationship they have with the school system. It is also important to mention that in a more recent perspective of family resilience (Luthar, Cicchetti, \& Becker, 2000, Walsh, 2003), the experience of parents raising children with disabilities has also been seen through the lens of the positive changes that a child with disability can determine in a family system. As a consequence of major distress, crisis, difficult challenges, the family can become stronger, can develop its resources and can grow.

Given the need to develop an accurate image of parental characteristics, the use of valid measurements for parental distress and psychological well-being becomes of high importance for professionals. The present study discusses the results obtained in two researches we conducted, regarding the cultural adaptation of two assessment scales of parental distress and psychological well-being, tools that proved increased potential to be used in research and clinical and psychopedagogical practice.

\section{Parental distress and its assessment}

The challenges and emotional demands of parents raising children with disabilities are higher compared with the challenges of parents with children without disabilities, which means that the level of parental distress is higher. The parents' burdens derive from the contextual barriers that they encounter in raising the child, but also from other sources referring to parental characteristics, as well as those of the child with disabilities. In the classical definition of Lazarus and Folkman (1984), distress appears when the perceived demands of a situation overcome the perceived coping resources of the system (individual, family, group, community), especially when the well-being of the system is perceived and evaluated as being threatened. The authors emphasize the critical role of the cognitive and affective evaluations and other coping strategies in the regulation of distress level. Using adaptative coping strategies lowers the distress level and the nature of cognitions moderates the person's adjustment.

According to Crnic and Low (2002), stress is defined as an emotional and behavioral response of the individual to an unpleasant event. According to Abidin (1995), parental distress represents the level of dysfunction within the parent-child system, mainly related to the level of parental functioning. Parental distress includes subjective feelings of emotional availability towards the child, trust and level of investment in the relationship with the child. A large number of studies conducted in the last decades examined parental distress in mothers and fathers of children with disabilities. A certain level of distress is considered normal and even adaptative for all the parents (Crnic, Gaze, \& Hoffman, 2005), but parents of children with neurodevelopmental disorders reported higher levels of distress at different ages of the child: early childhood (Jeans, Santos, Laxman, McBride, \& Dyer, 2013) and adolescence. These higher levels of distress proved to remain stable or increased during child development.

Parental distress remains a subject of debate for many researchers, as it is associated with other aspects of parental psychological well-being, including depression, marital conflict and precarious physical health (Woodman, Mawdsley, \& Hauser-Cram, 2014).

In parents of children with disabilities, the level of distress is directly related with the level of the child's functioning, his behavioral problems and the lack of prosocial behaviors. Parental distress correlates with the level of parental quality of life, on a physical, but also psychological level. The difficulties encountered by the parents of children with disabilities depend mainly on the type of disability. Children with developmental disorders, physical disabilities, visual and hearing impairments, chronical medical conditions, challenging behaviors require a higher level of parenting skills, compared to those required for children with typical development. Studies showed an increased level of parental distress in parents of children with behavioral disorders (hyperactivity, oppositionism) and visual and hearing impairments (Hilliard, Monaghan, Cogen, \& Streisand, 2011; Quittner, Barker, Cruz, Snell, Grimley, \& Botteri, 2010).

The situation of parents with children with autistic spectrum disorder (ASD) remains particular, given that the specialized literature reports extremely high levels of parental distress, thus making them the subject of a problematic clinical domain, despite the numerous scientific researches, diverse therapies and raised awareness in the population. Studies in which the target group was constituted by mothers of children with ASD, showed that $75 \%$ presented a very high level of distress, with scores above the clinical cut-off point (Hastings, 2008). Moreover, this distress level is maintained for a period of two years, emphasizing the importance of 
maintaining factors related to distress within the families of children with ASD (Dabrowska \& Pisula, 2010; Hastings, Daley, Burns, \& Beck, 2006; Hastings, 2008). Some researches found similar levels of distress in mothers and fathers from families of children with ASD (Hastings, 2003), while other more recent studies show a higher level in mothers (Dabrowska \& Pisula, 2010).

Maternal distress is related mainly with the problems of the child in the areas of feeding, sleeping, emotional regulation, while paternal distress is associated mainly with the problems of externalizing behavior manifested by the child (Davis \& Carter, 2008).

Despite these elements that differentiate the levels of maternal and parental distress, the negative consequences of distress are similar, manifested objectively at the level of relationship with the child, at the level of well-being and the parental quality of life. The negative effects of distress include mental health problems, influencing interpersonal relationships and the level of social adaptation. A metaanalysis of 18 studies showed a significant increase of the incidence of depressive symptoms in parents of children with disabilities and neurodevelopmental disorders (Singer, 2006). The negative influences overcome the preoccupations related to mental health (symptoms of anxiety and depression) and extend to more general problems of the quality of life, including parental competence and, in some cases, the incapacity to consider the positive aspects of being a parent (Tomanik, Harris, \& Hawkins, 2004).

In this context, we can mention the results obtained by Kayfitz, Gragg and Orr (2010), in a study that investigated the perspectives that parents of children with ASD had on parenting, referring to a reduced number of positive experiences and a high level of distress. The positive experiences included some direct contributions from the child (improvement of family relationships, source of happiness), and some indirect contributions of the child for the parent (personal development, a better understanding of life goals).

Parents of children with ASD showed a lower level of adaptation (pessimism, distant relationships with the child, the absence of opportunities for socializing) compared with parents of children with Down syndrome, $\mathrm{X}$ fragile syndrome and other disabilities (Abbeduto, Seltzer, Shattuck, Krauss, Orsmond, \& Murphy, 2004).
Another result worth mentioning is that a higher level of parental distress was found to be associated with a higher incidence of behavioural problems of the child, with the progress and the response of the child to intervention and therapy (Costea-Bărluțiu, Bălaş-Baconschi，\& Hathazi, 2014). One of the causes for lower outcomes can be related to the decreased availability for therapy. In the case of parents confronted with higher levels of distress, the cognitive and emotional resources they can use are greatly diminished, affecting their ability to continue and generalize the components and requirements of the therapy that the child follows (Rao \& Beidel, 2009).

Another related variable is the social support, that was considered an important mediator in the management of distress, but, as studies demonstrate, many families of children with disabilities find it difficult to visit their friends, mentioning the loss of many friendships due to the problems. The parents report being confronted with perturbances within daily routines, such as going to shopping, in order to avoid the public exposure of disruptive behaviors manifested by their children (CosteaBărluțiu, Bălaș-Baconschi, \& Hathazi, 2014).

Many parents and siblings of children with different disorders are obliged to face a real social stigma associated with their particularities (Francis, 2012). Some of the parents try hard to keep an adequate job and a subsequent satisfactory life standard, aspects that can be challenging due to the presence of a child with disability in the family (McConnell, Savage, \& Breitkreutz, 2014). Many parents are really overwhelmed by the challenges of finding jobs that are sometimes very rigid or provide minimal resources (Browne, Rokeach, Wiener, Hoch, Meunier, \& Thurston, 2013).

Parental distress was used as a mediating factor for determining the level of psychological well-being in parents of children with intellectual disabilities. According to a study by Cramm \& Nieboer (2011) parental distress is a strong predictor of psychological well-being, leading sometimes to the parents' decision to apply for placement services for their children. The authors specify that it is extremely important to identify the factors that influence psychological well-being in those parents that manifest the highest distress levels, with the aim to identify various services that could support the needs of the parents and their children, thus leading to avoidance of the placement of the child outside the family environment. 


\subsection{The assessment of parental distress}

Although some assessment measures for the level of distress include items concerning parental distress, most of these measures do not explicitly operationalize the distress associated to the parental role. The Parental Stress Scale (PSS, Berry \& Jones, 1995) is a measure with a wide applicability whose items are formulated in an accessible way (Oronoz, Alonso-Arbiol, \& Balluerka, 2007). The scale assesses the level of distress associated with raising a child, generated by the parental role itself.

The validity of the original version of the scale was tested on several groups of parents (Berry \& Jones, 1995). In order to elaborate the measure, the authors conducted a review of the literature and identified several relevant themes and concepts involved in the operational definition of the construct, both from the point of view of the satisfaction and the difficulties encountered as a parent.

Therefore, the scale includes positive items, concerning emotional benefits (love: "My child(ren) is an important source of affection for me"), happiness ("I am happy in my role as a parent"), amusement ("I enjoy spending time with my child(ren)"), feeling of personal development and growth ("Having child(ren) gives me a more certain and optimistic view for the future") as well as negative items referring to the high amount of time and energy ("Caring for my child(ren) sometimes takes more time and energy than I have to give"), financial costs ("Having child(ren) has been a financial burden") and restricted opportunities ("Having child(ren) has meant having too few choices and too little control over my life"). The scale includes 18 items, half of them are associated with high levels of distress and the other half with low levels (Berry \& Jones, 1995).

From the point of view of the psychometric properties, the authors (Berry \& Jones, 1995) found an appropriate level of internal consistency for a group of 125 parents of typical children (alpha Cronbach .83), as well as the ability of the scale to discriminate between the parental distress of parents of children with behavioral and developmental disorders and the parental distress of parents with typical children.

The psychometric properties of the Romanian version of the scale was tested as part of a study conducted in order to assess the level of parental distress in parents of children with Down Syndrome and with Autistic Spectrum Disorders (Costea-Bărluțiu, Bălaș-Baconschi, \& Hathazi, 2014). The Romanian version was tested on 32 biological parents of children with ASD and Down Syndrome, with ages between 31 and 55 years $(M=40.1$, st. dev. $=6.08)$, most of them from urban areas, married, highly educated, employed as personal assistants for their children with disabilities aged between 4 and 16 years $(M=9.8$, st. dev.=3.04), most of them having typical siblings.

The psychometric properties of the Romanian version were adequate, the internal consistency being .84 , which shows that the scale could be a valid measure of parental distress for the Romanian population, also suitable for the assessment of parental distress of parents with children with disabilities. Given the small sample size, we recommend caution in the interpretation of results, as well as further testing of the validity of the scale.

\section{The psychological well-being and its assessment}

The concept of well-being was introduced by the World Health Organization in 1948, through the classical definition for health, focused on the individual assessment of well-being and, recently, on the well-being of children and the role played by the family in the provision of an optimal level (Wollny, Apps, \& Henricson, 2010). Wellbeing is a dynamic concept including subjective, social and psychological dimensions, as well as behaviors related to health (Ryff \& Keyes, 1995). Colomeischi (2015) introduces a discussion concerning a social approach on well-being, mentioning that well-being means being with the others, satisfying one's own personal needs, fulfilling one's objectives and ensuring one's quality of life. Aked, Marks, Cordon, and Thompson (2008) state that well-being compresses two elements: positive emotions and optimal functioning. Happiness, contentment, pleasure, curiosity and engagement are defining persons who live positive experiences, the level and the way of functioning having an equally important role. The authors claim that living positive experiences, controlling one's own life and assuming goals in life are attributes of well-being.

Subjective well-being produces individual and social benefits, and therefore a major objective is, from this perspective, increasing the level of well-being (Zhong \& Mitchell, 2010). The predictors of well-being can be divided in genetically determined factors, contextual factors and cognitions and positive intentional behaviors (Lyubomirsky et al., 2005, cited by Zhong \& Mitchell, 2010). Genetic factors and character are responsible for 40$55 \%$ of the variance in well-being, while contextual factors such as marital status and profession are responsible for 8$15 \%$ of the variance, explained by the hedonic adaptation, 
through which persons are rapidly adapting to life's circumstances by accepting constant and quite stable characteristics. Two general perspectives on well-being are mentioned as co-existing elements in contemporary psychological studies: the hedonic approach, concerning happiness, which defines well-being as a state of pleasure seeking and pain avoidance and eudaimonia approach, which focuses on meaning making and self-actualization, the degree of personal functioning (Ryan \& Deci, 2001). The hedonic vision views well-being as pleasure and happiness, while eudaimonia views well-being in terms of cultivating personal abilities and the contribution to a high level of well-being, according to the human nature and values, to the fulfillment of an authentic potential and the experience of a meaningful life (McMahan \& Estes, 2011).

Various studies emphasized that positive subjective well-being corelates with different aspects of spending free time, including visiting family and friends, playing sports and games, listening to the radio, travelling, using internet (Newman, Tay, \& Diener, 2014). The authors mention the triadic model of subjective well-being, proposed by Diener in 1984, consisting in life satisfaction, high positive emotions and low negative emotions (Newman, Tay, \& Diener, 2014). Life satisfaction consists in a general evaluation of life as more or less satisfactory, while the positive or negative emotions are connected to positive or negative experiences in life. Emotions are adaptive experiences with physiological and subjective components, reactions and behavioral responses with an adaptative value (Charles, 2010). The emotional well-being depends on the emotional regulation, which includes external and internal individual physiological, cognitive and behavioral processes. The processing and emotional regulation models concern voluntary activities; therefore, the individual is behaving as a result of the exposure to relevant events, which produce an emotional response.

According to Bujor and Turliuc (2016), the predictors of well-being can be included in three over ordinate variable categories: personality, family and emotional regulation mechanisms (Bujor \& Turliuc, 2016). Therefore, wellbeing is influenced by the joint action of different factors involved in different stages of each person's life: personality factors, representing the internal dimension, family, related to the strategies used by parents for the socialization of emotions in the children's early life, as well as the quality of interactions during adolescence and youth. In their study, Bujor and Turliuc (2014) found that emotional stability becomes a significant predictive factor for all the dimensions: positive emotions, negative emotions, emotional distress and life satisfaction. Wellbeing is also tightly connected to an optimal quality of life; one of the concepts proposed by Aristotle, eudaimonia refers to the encouragement of individuals to use their potential to the maximum, in order to have a "good life". Diener and Suh (1997), citing Brock (1993), identify three major philosophical approaches of the quality of life, related to well-being: the first approach describes the characteristics of a satisfactory life conducted by norms and ideals that are religious, philosophical or based upon other systems. The second approach consists in satisfying preferences, namely within the constraints of resources, individuals are expected to select those things that would increase their quality of life. The third approach is constructed in individual terms, namely the extent in which individuals experience their life as satisfactory and pleasant, while factors as happiness, content and life satisfaction are considered relevant.

In the context of the constrains determined by the available resources, well-being also refers to the individual abilities, to authentic qualities that occur naturally, the inner motivation of each person that lead to a growth of the expected results (Brdar \& Kashdar, 2010). The two authors refer to the studies that identified the most relevant positive character features for a high level of well-being, for rehabilitation in illness states, as well as for the subjectively perceived psychological growth after the exposure to adversity (Park et al., 2004; Peterson et al., 2007, Peterson, Park and Seligman, 2006, Peterson et al., 2008, cited by Brdar \& Kashdar, 2010). These positive features offer a better understanding of what contributes to selfachievement, to satisfactory relationships, to selforganization, subjective vitality and satisfying psychological needs, such as autonomy, affiliation and competence, motivation for a pleasant, significant and engaging life. Park, Peterson, and Seligman (2004) proposed the Values in Action Inventory of Strengths, through which they identified the criteria and the classifications of those character features, connected to well-being. Out of the 24 features proposed by Park, Peterson and Seligman (2004), we can recall: curiosity, bravery, honesty, teamwork, leadership, humility, hope, gratitude, humor, and spirituality. Related to subjective well-being, a plethora of studies approached human happiness, determined by contextual and personal factors, as well as integrating, contextual and individual factors (Galinha \& Pais-Ribeiro, 2011). 
An initial classification of psychological processes (affiliation, control, meaning and autonomy) includes several theories: Maslow (1954), Ryff and Keyes (1995), Ryan and Deci (2001) and Csikszentmihalyi (1990) (cited by Galinha \& Pais-Ribeiro, 2011), and stresses out the need for the fulfillment of psychological needs in connection with these processes. Therefore, Maslow's theory regarding the hierarchy of needs claims that affiliation is necessary in different stages of individual well-being; the six factor model of subjective well-being proposed by Ryff and Keyes (1995) supports experiences of autonomy, control, meaning and affiliation, while Ryan and Deci (2001) mention that reaching autonomy, closeness and competence leads to a state of psychological well-being.

\section{Assessment of the psychological well-being}

The instrument adapted for the assessment of psychological well-being, the Ryff Scale for Psychological Well-Being, PWB, developed by Ryff (1989), is based on the author's theory on eudaimonic well-being and it operationalizes the construct on the six dimensions of the model (Ryff \& Keyes, 1995). Several versions of the instrument were developed and tested on various cultures and we chose to adapt for the Romanian population the medium 54-item version, with 9 item on each subscale. Each item is scored on a 6-point Likert scale, ranging from 1 (strong disagreement) to 6 (strong agreement), with some of the items reverse scored.

A brief description and some examples of items for each of the 6 subscale are listed below:

1. Self-Acceptance: a positive regard on oneself and acceptance of past life experiences, eg. "When I look at the story of my life, I am pleased with how things have turned out";

2. Positive relations with others: a general satisfaction with one's relationships, profound connections, empathy and care towards others, eg. "Most people see me as loving and affectionate";

3. Autonomy: independence, self-determination, liberty regarding rules and norms, eg. "My decisions are not usually influenced by what everyone else is doing";

4. Purpose in Life: a perspective on life as being meaningful, eg. "I enjoy making plans for the future and working to make them a reality";
5. Environmental Mastery: a sense of competency in managing challenges, taking actions and problem solving, eg. "In general, I feel I am in charge of the situation in which I live";

6. Personal Growth: the openness towards new experiences, progress, self-actualization, selfefficacy, eg. "I think it is important to have new experiences that challenge how you think about yourself and the world".

The scale was widely used in research on psychological wel-being, but its psychometric properties and factor structure are still being disputed. The version we adapted for the Romanian population was tested on a sample of 239 participants, out of which 148 were students with an average age of 20.13 years (SD 1.81) and 91 were parents of children with disabilities (Autistic traits and Down's Syndrome), with an average age of 39.72 years (SD 7.42). The sample was heterogenous, most of the participants were women, living in urban areas, involved in a couple relationship (either married couple or romantic relationship).

Although the correlated six-factor model proved to have several problems on the sample we tested it (a higher than accepted error of approximation and lower goodness-offit), it proved to be a better fit for the data, compared to the uncorrelated 6-factor model, a result similar to the one that other authors found on different cultures. The internal consistency was lower than the one reported by the authors of the original version of the scale. Alpha Cronbach was .76 for "Self-Acceptance" subscale, while for "Positive relations with others" we obtained a value of .695 , for "Autonomy" a value of .65, for "Purpose in Life" a value of .63, for "Environmental Mastery" a value of .75 and for "Personal Growth" a value of .65, some of them acceptable, but others questionable values. All the six subscales were significantly intercorrelated, but the correlation between "Purpose in Life" and "Autonomy" subscales was weak (Costea-Bărluțiu，Bălaș-Baconschi，\& Hathazi, 2018). Although we found and discussed several problems of the scale adapted for the Romanian population, the 6-factor model was considered acceptable, and the scale was considered fit to be used on the Romanian population, given the strong theoretical support of the underlying construct. However, we recommend the further testing of the scale and its cautious use until the model is fully validated. 


\section{Conclusions}

Despite the limitations we found for the two scales, both the instrument for the assessment of parental distress and the one for the psychological well-being were considered useful in practice and research for parents of children with disabilities. Given that parental health and the way in which the parents adapt to the child's disability are relevant aspects for the parental involvement in the child's education and rehabilitaton, the need to adapt measures that help monitor the intervention is crucial.

Based on the assessment, the professionals can develop intervention programs targeting the optimal stress management (by using such techniques as Stress Inoculation, Meichenbaum, 1977, 1985, cited by Meichenbaum, 2007, according to which the short term, gradual exposure to stress contributes to the development of corrective mechanisms that buffer against more intense stressors, by the development of coping strategies and resilience and the Self-instructional training, developed by the same author, that represents a simple "mental repetition" method, using internalized, indirect selfassertions, aimed at self-guidance in difficult situations and behavior modification, as well as the development of coping strategies that approach the problematic internal dialogue and the formulation of more positive selfassertions), as well as the increase of psychological wellbeing, in order to prevent the fatigue, the debut of psychopathology and to optimize functioning.

Such programs as the support groups for parents, the "School for Parents", counselling for parents, meetings with parents and psychoeducation on the role of parental well-being in the approach that parents have with their own child, in the cooperation between parents and schools, can use the assessment instruments adapted in our research, in order to monitor the parents' progress regarding their distress level and their psychological well-being.

\section{Authors note:}

Carmen Costea-Bărluțiu, Ph.D. is Lecturer at the Special Education Department, Faculty of Psychology and Educational Sciences, with $\mathrm{PhD}$ in Psychology and Psychotherapist in private practice. Her research interests include: individual and family mental health and wellbeing, attachment, effect of disability and illness on adjustment.
Andrea Hathazi, Ph.D. is Associate Professor at the Special Education Department, Faculty of Psychology and Educational Sciences, with $\mathrm{PhD}$ in Psychology. Her research activity is centered around: children with multiple disabilities, with Down Syndrome, alternative and augmentative communication, visual impairments.

Cristina Bălaș-Baconschi, Ph.D. is Lecturer at the Special Education Department, Faculty of Psychology and Educational Sciences, with $\mathrm{PhD}$ in Psychology. Her research interests include: autistic spectrum disorders, social and emotional disorders, intellectual disabilities.

\section{References}

Abbeduto, L., Seltzer, M., Shattuck, P., Krauss, M., Orsmond, G., \& Murphy, M.M. (2004). Psychological well-being and coping in mothers of youths with autism, Down syndrome, or fragile X syndrome. American Journal on Mental Retardation, 109, 237-254.

Abidin, R.R. (1995) Parenting Stress Index manual. 3rd ed. Odessa, FL: Psychological Assessment Resources.

Agazio, J.B., \& Buckley, K.M. (2012). Revision of a Parental Stress Scale for Use on a Pediatric General Care Unit. Pediatric Nursing, 38(2), 82-87.

Aked, J., Marks, N., Cordon, C., \& Thompson, S. (2008). Five Ways to Wellbeing: The Evidence. New Economics Foundation, neweconomics.org.

Beck, A., Hastings, R.P., Daley, D., \& Stevenson, J. (2004). Pro-social behavior and behavior problems independently predict maternal stress. Journal of Intellectual \& Developmental Disability, 29(4), 339-349.

Berry, J.O., \& Jones, W.H. (1995). The Parental Stress Scale: Initial psychometric evidence. Journal of Social and Personal Relationships, 12(3), 463-472.

Brdar, I., \& Kashdan, T.B. (2010). Character strengths and wellbeing in Croatia: An empirical investigation of structure and correlates. Journal of Research in Personality, 44, 151154.

Browne, D.T., Rokeach, A., Wiener, J., Hoch, J.S., Meunier, J.C., \& Thurston, S. (2013). Examining the family-level and economic impact of complex child disabilities as a function of child hyperactivity and service integration. Journal of Developmental and Physical Disabilities, 25(2), 181-201.

Bujor, L., \& Turliuc, M.N. (2016). Predictors of well-being: An examination of age differences. Annals of A.I. Cuza University Psychology Series, 25(1), 5-16.

Charles, S.T. (2010). Strength and vulnerability integration: a model of emotional well-being across adulthood. Psychological Bulletin, 136(6), 1068.

Colomeischi, A.A. (2015). Emotional Life as Influence on Work Satisfaction. Procedia - Social and Behavioral Sciences, 159(23), 350-354. 
Costea-Bărluțiu, C., Bălaș-Baconschi, C., \& Hathazi, A. (2014). A Preliminary Investigation of a Parental Stress measure for Parents of Children with Autism Spectrum Disorders and Down Syndrome. Studia Universitatis Babeș-Bolyai, Psychologia-Paedagogia, 59(2), 25-40.

Costea-Bărluțiu, C., Bălaș-Baconschi, C., \& Hathazi, A. (2018). Romanian Adaptation of the Ryff's Psychological WellBeing Scale: Brief Report of the Factor Structure and Psychometric Properties. Journal of Evidence-Based Psychotherapies, 18(1), 21-33.

Cramm, J.M., \& Nieboer, A.P. (2011). Psychological well-being of caregivers of children with intellectual disabilities: Using parental stress as a mediating factor. Journal of Intellectual Disabilities, 15(2), 101-113.

Crnic K.A., Gaze C., \& Hoffman C. (2005). Cumulative parenting stress across the preschool period: Relations to maternal parenting and child behavior at age 5. Infant and Child Development. 14(2), 117-132.

Crnic, KA., \& Low, C. (2002) Everyday stresses and parenting. In Bornstein, M.H. (ed.). Handbook of Parenting, Volume 5: Practical Issues in Parenting. 2nd ed. Mahwah, NJ: Lawrence Earlbaum, 243-268.

Dabrowska, A.A., Pisula, E.E. (2010). Parenting stress and coping styles in mothers and fathers of pre-school children with autism and Down syndrome. Journal of Intellectual Disability Research, 54(3), 266-280.

Davis, N., \& Carter, A.S. (2008). Parenting stress in mothers and fathers of toddlers with autism spectrum disorders: Associations with child characteristics. Journal of Autism and Developmental Disorders, 38(7), 127.

Diener, E., \& Suh, E. (1997). Measuring quality of life: Economic, social, and subjective indicators. Social indicators research, 40(1), 189-216.

Francis, A. (2012). Stigma in an era of medicalization and anxious parenting: How proximity and culpability shape middle-class parents' experiences of disgrace. Sociology of Health \& Illness, 34(6), 927-942.

Galinha, I.C., \& Pais-Ribeiro, J.L. (2011). Cognitive, affective and contextual predictors of subjective wellbeing. International Journal of Wellbeing, 34-53.

Hastings, R.P. (2003). Child behavior problems and partner mental health as correlates of stress in mothers and fathers of children with autism. Journal of Intellectual Disability Research, 47(4-5), 231-237.

Hastings, R.P. (2008). Stress in parents of children with autism. In E. McGregor, M. Núñez, K. Cebula, \& J. Gómez (Eds.). Autism: An integrated view from neurocognitive, clinical, and intervention research, 303-324.

Hastings, R.P., Daley, D., Burns, C., \& Beck, A. (2006). Maternal distress and expressed emotion: Cross-sectional and longitudinal relationships with behavior problems of children with intellectual disabilities. American Journal on Mental Retardation, 111, 48-61.

Hilliard, M.E., Monaghan, M.M., Cogen, F.R., \& Streisand, R.R. (2011). Parent stress and child behavior among young children with type 1 diabetes. Child: Care, Health and Development, 37(2), 224-232.

Jeans, L.M., Santos, R.M., Laxman, D.J., McBride, B.A., \& Dyer, W.J. (2013) Examining ECLS-B maternal stress and depressive symptoms when raising children with ASD. Topics in Early Childhood Special Education, 33(3), 162171.

Kayfitz, A.D., Gragg, M.N., \& Orr, R. (2010). Positive experiences of mothers and fathers of children with autism. Journal of Applied Research in Intellectual Disabilities, 23(4), 337-343.

Lazarus, S.R., \& Folkman, S. (1984). Stress, Appraisal, and Coping, New York: Springer Publishing Company.

Luthar, S.S., Cicchetti, D., \& Becker, B. (2000). The Construct of Resilience: A Critical Evaluation and Guidelines for Future Work. Child Development, 71(3), 543-562.

McConnell, D., Savage, A., \& Breitkreutz, R. (2014). Resilience in families raising children with disabilities and behavior problems. Research in Developmental Disabilities, 35, 833848.

McMahan, E. A., \& Estes, D. (2011). Hedonic versus eudaimonic conceptions of well-being: Evidence of differential associations with self-reported well-being. Social Indicators Research, 103(1), 93-108.

Meichenbaum, D. (2007). Stress Inoculation Training: A Preventative and Treatment Approach. In Lehrer, P.M., Woolfolk, R.L., \& Sime, W.S. (eds.). Principles and Practice of Stress Management, 3rd ed., New York: Guilford Press.

Newman, D.B., Tay, L., \& Diener, E. (2014). Leisure and subjective well-being: A model of psychological mechanisms as mediating factors. Journal of Happiness Studies, 15(3), 555-578.

Oronoz, B., Alonso-Arbiol, I., \& Balluerka, N. (2007). A Spanish adaptation of the Parental Stress Scale. Psicothema, 19(4), 687-692.

Park, N., Peterson, C., \& Seligman, M.E. (2004). Strengths of character and well-being. Journal of social and Clinical Psychology, 23(5), 603-619.

Quittner, A.L., Barker, D.H., Cruz, I., Snell, C., Grimley, M.E., \& Botteri, M. (2010). Parenting stress among parents of deaf and hearing children: Associations withlanguage delays and behavior problems. Parenting: Science and Practice, 10(2), 136-155.

Rao, P.A., \& Beidel, D.C. (2009). The impact of children with high-functioning autism on parental stress, sibling adjustment, and family functioning. Behavior Modification, 33(4), 437-451.

Rogers, M.A., Wiener, J., Marton, I., \& Tannock, R. (2009). Supportive and Controlling Parental Involvement as Predictors of Children's Academic Achievement: Relations to Children's ADHD Symptoms and Parenting Stress. School Mental Health, 1, 89-102. 
Ryan, R.M., \& Deci, E.L. (2001). On happiness and human potentials: A review of research on hedonic and eudaimonic well-being. Annual Review of Psychology, 52,141-166.

Ryff, C.D. (1989). "Happiness is everything, or is it?" Explorations on the meaning of psychological well-being. Journal of Personality and Social Psychology, 57, 10691081.

Ryff, C.D., \& Keys. C. (1995). The structure of psychological well-being revisited. Journal of Personality and Social Psychology, 69: 719-727.

Singer, G.S. (2006). Meta-analysis of comparative studies of depression in mothers of children with and without developmental disabilities. American Journal on Mental Retardation, 111(3), 155-169.

Tomanik, S., Harris, G.E., \& Hawkins, J. (2004). The relationship between behaviors exhibited by children with autism and maternal stress. Journal of Intellectual and Developmental Disability, 29(1), 16-26.

Walsh, F. (2003). Family Resilience: A Framework for Clinical Practice. Family Process, 42(1), 1-18.

Wollny, I., Apps J., \& Henricson, C. (2010). Can government measure family wellbeing? London: Family and Parenting Institute.

Woodman, A.C., Mawdsley, H.P., \& Hauser-Cram, P. (2014). Parenting Stress and Child Behavior Problems within Families of Children with Developmental Disabilities: Transactional Relations across 15 Years. Research in Developmental Disabilities, 36, 264-276.

Zhong, J.Y., \& Mitchell, V.W. (2010). A mechanism model of the effect of hedonic product consumption on well-being. Journal of Consumer Psychology, 20(2), 152-162. 